\title{
Eficácia do herbicida acetochlor na semeadura direta e convencional com ou sem palha e os efeitos sobre o rendimento do milho
}

\author{
Acetochlor herbicide efficacy on tillage and no-tillage systems on straw mulch presence or \\ absence and effect on corn yield
}

\author{
Miguel Vicente Weiss Ferri' ${ }^{1}$ Ribas Antonio Vidal ${ }^{2}$
}

RESUMO

O experimento foi conduzido na Faculdade de Agronomia da Universidade Federal do Rio Grande do Sul, ano agrícola de 2000/2001, com o objetivo de avaliar a eficácia de controle das plantas daninhas com o herbicida acetochlor em Argissolo Vermelho, conduzido sob semeadura direta e preparo convencional, na presença ou ausência de palha. $O$ delineamento experimental utilizado foi blocos casualizados com quatro repetições. Os tratamentos constaram de acetochlor nas doses de 0, 1680, 3360 e 5040 $\mathrm{g} \mathrm{h}^{-1}$, aplicado em solo sob semeadura direta e preparo convencional, na presença $\left(4,5 t h \mathrm{~h}^{-1}\right)$ ou ausência de palha de aveia. Foram avaliados o controle das plantas daninhas, além da altura de plantas e rendimento de grãos de milho. $O$ acetochlor foi mais eficiente para o controle das plantas daninhas no preparo convencional, comparado à semeadura direta. A palha reduziu a eficácia de controle pelo acetochlor. A altura das plantas de milho foi maior na semeadura direta. $O$ rendimento de grãos de milho foi maior no preparo convencional e na presença da palha devido ao melhor controle das plantas daninhas.

Palavras chave: adsorção, degradação biológica, persistência.

\section{ABSTRACT}

An experiment was carried out at Federal University at Rio Grande do Sul, with the objective of avaluating herbicide acetochlor efficacy on conventional tillage and no-till soils. The soil is classified as at Paleudult. The following treatments were tested: acetochlor at 0, 1680, 3360 and 5040 $\mathrm{g} \mathrm{h}^{-1}$, applied on tillage and no-tillage systems on oat straw mulch presence $\left(4,5 t \mathrm{ha}^{-1}\right)$ and absence. Assessements included crop injury, weed control at 15, 30 and 45 days after herbicide application, and corn crop yeld. The weed control with acetochlor herbicide was more efficient on tillage than on no-tillage system. Straw mulch reduced acetochlor herbicide weed control. Corn plant height was higher on no-tillage than on tillage systems, indicating lower herbicide activity on the first. Corn yield was higher on tillage system and straw mulch presence, due to better weed control.

Key words: adsorption, microbial degradation, persistence.

\section{INTRODUÇÃO}

A expressão do potencial produtivo pelas culturas exige, entre outros, o adequado controle das plantas daninhas. O controle é necessário, pois as plantas daninhas competem por água, luz, nutrientes e espaço físico. As plantas daninhas também interferem com as culturas por abrigarem pragas, patógenos e nematóides, além de dificultarem ou inviabilizarem a colheita das mesmas. $\mathrm{O}$ ambiente de interferência originado, normalmente resulta em prejuízos qualitativos e quantitativos à produção agrícola (DURIGAN et al., 1983; FLECK et al., 1989).

A absorção dos herbicidas aplicados no solo pelas raízes das plantas daninhas, e a conseqüente eficácia de controle das mesmas é determinada por processos que regulam a concentração e a persistência das moléculas na solução do solo. Dentre estes processos, destacam-se a lixiviação, a degradação e/ ou transformação biológica, a adsorção ao solo (MOYER et al., 1987; LEVANON et al., 1993).

A eficácia de controle das plantas daninhas pelos herbicidas cloroacetamidas pode variar com o conteúdo de argila, umidade e matéria orgânica do solo, devido aos efeitos destes fatores sobre a adsorção destes herbicidas no solo(WEBER \& PETER, 1982; MUELLER et al., 1999). A meia vida $\left(t_{1 / 2}\right)$ e o conseqüente controle das plantas daninhas, do herbicida alachlor variou entre 6 e 60 dias, dependendo da temperatura, umidade e teor de matéria orgânica do solo. A persistência neste caso, reduziu com o incremento da atividade e biomassa microbiana do solo (WALKER et al., 1992; MUELLER et al., 1999). Em função do transporte das moléculas dos herbicidas para além do alcance das raízes das plantas daninhas, a lixiviação

\footnotetext{
'Engenheiro Agrônomo, Doutor, CP 138, 85550-000, Coronel Vivida, Pr. E-mail: @mvwferri@bol.com.br

${ }^{2}$ Engenheiro Agrônomo, PhD, Professor, Departamento de Plantas de Lavoura, Faculdade de Agronomia, Universidade Federal do Rio Grande do Sul. Av. Bento Gonçalves, 7712, 91501-970, Porto Alegre, RS. E-mail: vidal@ vortex.ufrgs.br.
} 
também reduziu a eficácia de controle dos herbicidas cloroacetamidas (PETER \& WEBER, 1985).

A semeadura direta, devido à não mobilização e à manutenção da palha na superfície do solo, eleva o teor superficial de matéria orgânica, mantém a estabilidade da estrutura e reduz as amplitudes de variações de temperatura e umidade do solo. Além disso, este sistema de manejo, normalmente incrementa a atividade e a biomassa microbiana do solo. Cria-se, desta forma, condições favoráveis à dissipação e redução da eficácia de controle da plantas daninhas pelos herbicidas residuais, através do aumento da adsorção, degradação biológica e da lixiviação destes compostos no solo (LEVANON et al., 1993; FUSCALDO et al., 1999).

A cobertura do solo com palha também pode afetar a eficácia de controle dos herbicidas residuais. A intensidade da ação depende da quantidade e do grau de decomposição da palha. O aumento na quantidade e a presença de resíduos bem decomposto pode aumentar a adsorção e prolongar o tempo de residência dos herbicidas na superfície do solo, reduzindo assim, a absorção pelas raízes da plantas daninhas (ADDISCOTT \& DEXTER, 1994; REDDY et al., 1995).

Em função da presença da palha como cobertura do solo e de seus efeitos sobre os teores de matéria orgânica, umidade, biomassa e atividade microbiana, a semeadura direta pode afetar a eficácia de controle das plantas daninhas pelos herbicidas aplicados ao solo. O menor controle esperado, pode favorecer a interferência com as culturas e reduzir a produtividade das mesmas. Este trabalho tem por objetivo avaliar o controle das plantas daninhas pelo herbicida acetochlor em solo sob semeadura direta e preparo convencional na presença e ausência de palha e as consequiências no rendimentos de grãos pela cultura do milho.

\section{MATERIALEMÉTODOS}

O experimento foi conduzido no ano agrícola 2000/2001, na Estação Experimental Agronômica da Universidade Federal do Rio Grande do Sul (EEA/UFRGS), localizada no município de Eldorado do Sul, região fisiográfica da Depressão Central do Estado. O solo do local pertence à unidade de mapeamento São Jerônimo, sendo classificado como Argissolo Vermelho distrófico típico. Os manejos adotados foram semeadura direta (sete anos consecutivos) e preparo convencional (arações e gradagens anuais e 15 anos consecutivos).

$\mathrm{O}$ acetochlor, (2-cloro-N-(etoximetil)-N-(2etil-6-metil-fenil) acetamida), pertence ao grupo das cloroacetamidas. Este herbicida foi aplicado com pulverizador costal pressurizado com $\mathrm{CO}_{2}$, na pressão de $200 \mathrm{kPa}$, bicos tipo leque 8002, distanciados em $0,50 \mathrm{~m}$ na barra de $1,5 \mathrm{~m}$ e volume de calda de $220 \mathrm{~L} \mathrm{ha}^{-1}$.

O preparo da área experimental na semeadura direta consistiu na dessecação da vegetação existente com paraquat $\left(800 \mathrm{~g} \mathrm{ha}^{-1}\right)$, sete dias antes e no dia da implementação dos tratamentos. As principais plantas daninhas presentes na área experimental foram Digitaria sp. Wild (milhã), Bidens pilosa L. (picãopreto), Sida spp. (guanxuma) e Brachiaria plantaginea (Link) Hitchc. (papuã).

O delineamento experimental utilizado foi blocos casualizados com quatro repetições, sendo os tratamentos distribuídos em parcelas subsub-subdivididas. As unidades experimentais mediram $2 \times 4 \mathrm{~m}$. Nas parcelas principais, encontravam-se o preparo do solo: semeadura direta e preparo convencional; nas subparcelas a cobertura do solo: com $\left(4,5 \mathrm{tha}^{-1}\right)$ e sem palha; nas subsubparcelas as doses do herbicida acetochlor: 0, 1680, 3360 e $5040 \mathrm{~g} \mathrm{ha}^{-1}$ e nas subsubsubparcelas as épocas de avaliação de controle das plantas daninhas: 15, 30 e 45 dias após aplicação do acetochlor (DAT). A cobertura do solo com palha foi obtida retirando-se a palha existente sobre a superfície do solo na semeadura direta, seguido da deposição de palha de aveia (Avena strigosa Schreb.) nos tratamentos com palha. No preparo convencional, o efeito da palha sobre eficácia de controle das plantas daninhas pelo acetochlor foi avaliado depositando-se palha de aveia no solo nos tratamentos com palha. Avaliou-se o controle das plantas daninhas, a altura das plantas aos 15 e 30 DAT e o rendimento de grãos de milho. O controle das plantas daninhas foi avaliado visualmente atribuindo-se notas que variaram de 0 para ausência e 100 para controle total das plantas. As alturas de plantas de milho foram obtidas, medindo-se, aleatoriamente, cinco plantas da parcela.

$\mathrm{Na}$ análise estatística, os dados relativos à porcentagem de controle das plantas daninhas sofreram transformações para arco seno $\sqrt{\mathrm{x} / 100}$, ao serem submetidos à análise de variância. Os efeitos quantitativos das doses do herbicida acetochlor foram avaliados através de análise de regressão, enquanto que os efeitos qualitativos dos sistemas de preparo e cobertura do solo com palha foram avaliados pelo teste de Tukey $(\mathrm{P} \leq 0,05)$.

\section{RESULTADOSEDISCUSSÃO}

Para a variável controle das plantas daninhas, ocorreu interação entre preparo de solo, doses do herbicida acetochlor e época de avaliação (Figuras 1 e 2). O acetochlor foi menos eficaz para o controle 


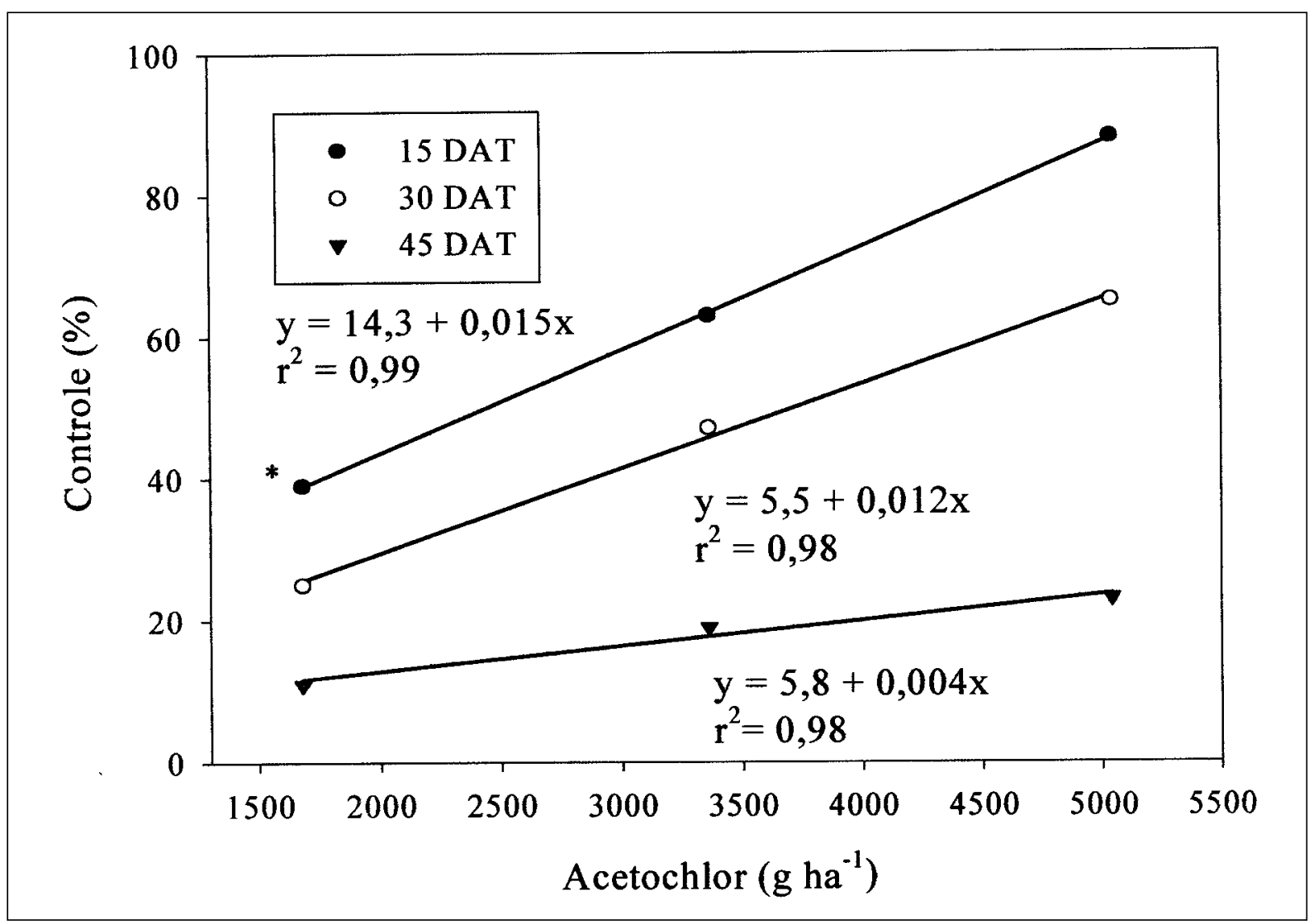

Figura 1 - Controle de plantas daninhas pelo herbicida acetochlor em diferentes épocas de avaliação no sistema de semeadura direta. *Todos os tratamentos nessa figura diferem dos tratamentos equivalentes na figura 2. EEA/UFRGS, Eldorado do Sul, RS, $2000 / 2001$.

das plantas daninhas na semeadura direta, comparada ao preparo convencional, em todas as doses utilizadas e épocas de avaliação (Figuras 1 e 2). Além disso, a comparação dos níveis de controle nas diferente épocas de avaliação demonstra que o herbicida acetochlor apresentou menor persistência na semeadura direta (Figuras 1 e 2). A atividade e a persistência e, por conseqüência, a eficácia de controle das plantas daninhas do herbicida acetochlor, pode variar no solo em função da adsorção, lixiviação e degradação e/ou transformação biológica, pois estes fatores regulam a concentração e a permanência de suas moléculas na solução do solo (PETER \& WEBER, 1985; WALKER et al., 1992; MUELLER et al., 1999). A semeadura direta, devido à não mobilização e a manutenção da palha na superfície do solo, eleva o teor superficial de matéria orgânica, mantém a estabilidade da estrutura e reduz as amplitudes de variações de temperatura e umidade do solo. Em função disso, criam-se condições favoráveis à dissipação e redução da eficácia de controle das plantas daninhas, através do incremento da adsorção, lixiviação e degradação biológica dos herbicidas aplicados no solo (LEVANON et al., 1993; FUSCALDO et al., 1999), sendo estas, possíveis explicações para o menor controle das plantas daninhas observado na semeadura direta, tanto na ausência quanto na presença da palha.

Alem disso, a expressão do potencial produtivo pelas culturas depende da intensidade, época e duração da interferência proporcionado pela presença das plantas daninhas nas lavouras (PITELLI, 1984; FLECK et al., 1989). Desta forma, considerandose $85 \%$, como o controle mínimo necessário para que as culturas expressem seu potencial produtivo e, que os períodos crítico e total de prevenção da interferência para culturas anuais como o milho, se estendem entre 25 e 30 dias e entre 40 e 50 dias de seu ciclo, respectivamente (DURIGAN et al., 1983; PITELLI, 1984), nenhuma das doses do acetochlor utilizadas, tanto na semeadura direta, quanto no preparo convencional (Figuras 1 e 2), proporcionaram controle satisfatório das plantas daninhas até 45 DAT. Para a semeadura direta, o controle das plantas daninhas pelo acetochlor foi ineficiente $(<70 \%)$ dentro do perío- 


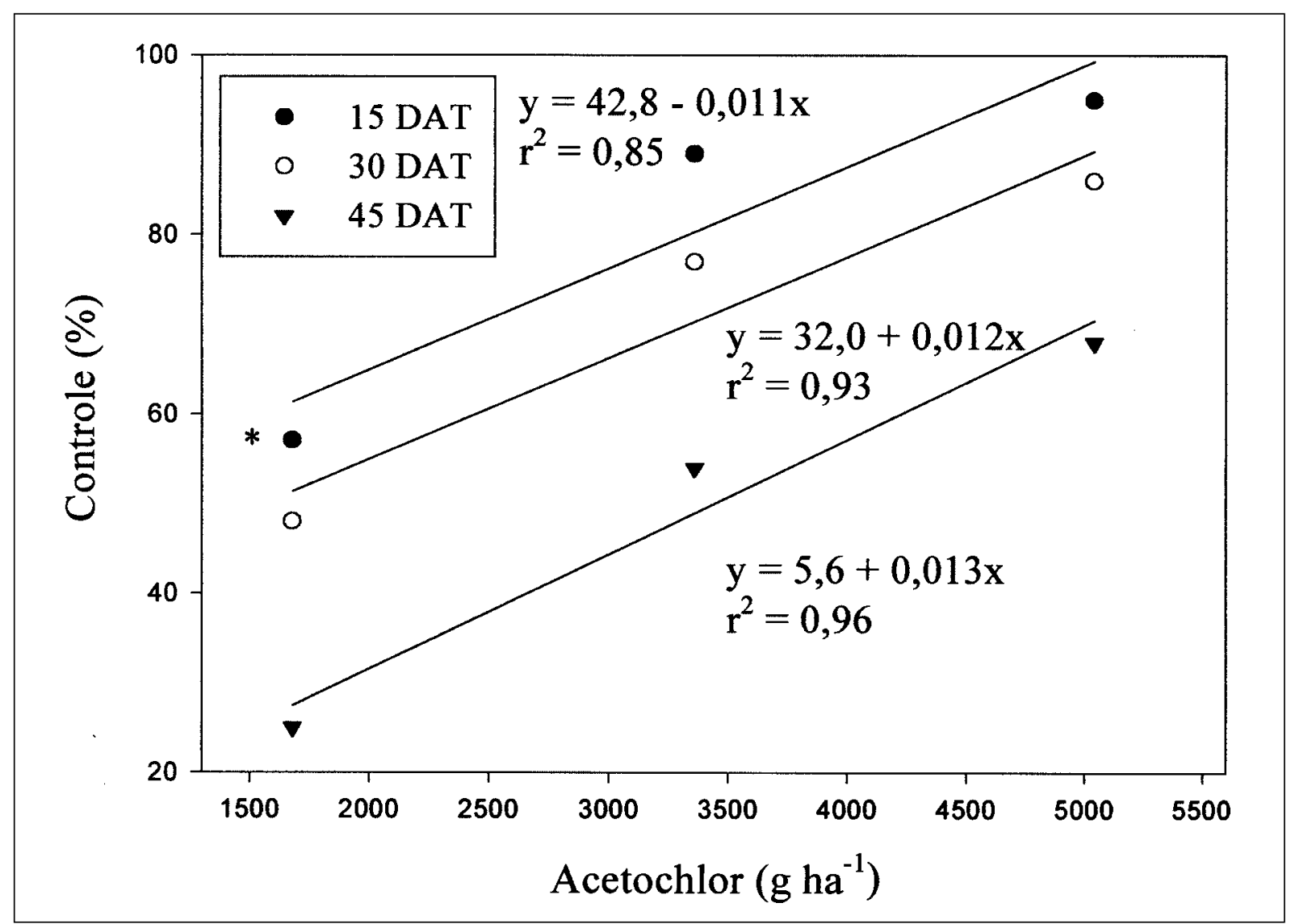

Figura 2 - Controle de plantas daninhas pelo herbicida acetochlor em diferentes épocas de avaliação e preparo convencional do solo. *Todos os tratamentos nessa figura diferem dos tratamentos equivalentes na figura 1. EEA/UFRGS, Eldorado do Sul, RS, $2000 / 2001$.

do crítico de prevenção da interferência (Figura 1).

Para a variável controle das plantas daninhas, também ocorreu interação entre preparo do solo, cobertura com palha e época de avaliação (Tabela 1). Com exceção da avaliação realizada aos 45 DAT e na semeadura direta, este herbicida apresentou menor controle das plantas na presença da palha em ambos as formas de preparo do solo. Além disso, o herbicida acetochlor apresentou menor controle das plantas daninhas na semeadura direta, quando comparado ao preparo convencional, tanto na presença quanto na ausência da palha sobre a superfície do solo (Tabela 1). A cobertura do solo com palha pode afetar a eficácia de controle pelos herbicidas residuais (BANKS \& ROBINSON, 1986). A intensidade da ação depende da quantidade e do grau de decomposição da palha presente na superfície do solo (ADDISCOTT \& DEXTER, 1994; REDDY et al., 1995). A cobertura do solo com palha afeta a atividade e, desta forma, a eficácia de controle do herbicida acetochlor (BANKS \&
Tabela 1 - Controle das plantas daninhas com o herbicida acetochlor em função do preparo (A), cobertura do solo com palha (B) e época de avaliação (C). EEA/UFRGS, Eldorado do Sul, RS, 2000/2001.

\begin{tabular}{|c|c|c|c|c|}
\hline \multirow{2}{*}{ Época } & \multicolumn{2}{|c|}{ Semeadura direta } & \multicolumn{2}{|c|}{ Semeadura convencional } \\
\hline & Com palha & Sem palha & Com palha & Sem palha \\
\hline $15 \mathrm{DAT}^{1}$ & ${ }^{2} \mathrm{f} 40 \mathrm{Aa}^{3}$ & $\mathrm{t} 45 \mathrm{Ab}$ & F $54 \mathrm{Aa}$ & T $63 \mathrm{Ab}$ \\
\hline $30 \mathrm{DAT}$ & f $24 \mathrm{Ba}$ & $\mathrm{t} 29 \mathrm{Bb}$ & F $43 \mathrm{Ba}$ & $\mathrm{T} 52 \mathrm{Bb}$ \\
\hline 45 DAT & f $11 \mathrm{Ca}$ & $\mathrm{t} 11 \mathrm{Ca}$ & F $25 \mathrm{Ca}$ & T $36 \mathrm{Cb}$ \\
\hline $\mathrm{CV} \mathrm{A}(\%)^{4}$ & \multicolumn{4}{|c|}{4,4} \\
\hline CV B $(\%)$ & \multicolumn{4}{|c|}{8,0} \\
\hline $\mathrm{CV} \mathrm{C}(\%)$ & \multicolumn{4}{|c|}{9,4} \\
\hline
\end{tabular}

${ }^{1} \mathrm{DAT}=$ dias após a aplicação de herbicidas.

${ }^{2}$ Médias antecedidas pela mesma letra maiúscula na linha não diferem pelo teste de Tukey $(\mathrm{P}>0,05)$.

${ }^{3}$ Médias seguidas pela mesma letra maiúscula na coluna e minúscula na linha, não diferem significativamente pelo teste de Tukey $(\mathrm{P}>$ $0,05)$.

${ }^{4} \mathrm{CV}=$ Coeficiente de variação. 
ROBINSON, 1986), sendo esta, possível explicação para o menor controle das plantas daninhas observada na presença da palha.

Para variável altura de plantas da milho ocorreu interação entre preparo do solo, dose do acetochlor e época de avaliação (Figura 3). Com exceção da avaliação realizada aos 15 DAT e para dose de acetochlor de $3360 \mathrm{~L} \mathrm{ha}^{-1}$, em que não se observou variação de altura de plantas entre as formas de preparo do solo avaliadas, a cultura do milho apresentou maior altura de plantas no solo sob semeadura direta, em ambas as épocas de avaliação e para as demais doses aspergidas. Apesar do controle mais eficiente das plantas daninhas (Figuras 1 e 2) resultar em menor interferência e poder favorecer o crescimento das plantas, tal resposta não foi observada no trabalho. Este resultado sugere que o acetochlor proporcionou maior injúria à cultura no preparo convencional.

O rendimento de grão de milho variou em função do preparo (Tabela 2) e cobertura do solo com palha (Tabela 2). Em relação à cobertura do solo com palha, observou-se que o rendimento de grãos foi su- perior na presença da palha (Tabela 2). Excetuando-se os efeitos da palha sobre o rendimento das culturas, como manutenção da umidade do solo e liberação de nutrientes através de sua degradação biológica, ela pode ter adsorvido o herbicida acetochlor e reduzido a injúria à cultura do milho. Em relação ao preparo do solo, observou-se maior rendimento de grãos no solo sob preparo convencional (Tabela 2). O controle de plantas daninhas inferior a $70 \%$ dentro do período crítico de prevenção da interferência (Figura 1), provavelmente contribuiu para manifestação deste resultado. Além disso, excluindo-se os efeitos do manejo do solo sobre o rendimento de grãos das culturas e, apesar da menor altura de plantas observada neste sistema de preparo do solo (Figura 3) sugerir perdas de rendimento por efeito fitotóxico, a menor interferência das plantas daninhas devido ao controle mais eficaz observado no preparo convencional (Figura 2), possivelmente tenha contribuído para o incremento do rendimento de grãos de milho neste sistema de manejo do solo.

Os resultados observados neste trabalho, demonstraram significativa variação de eficácia e ati-

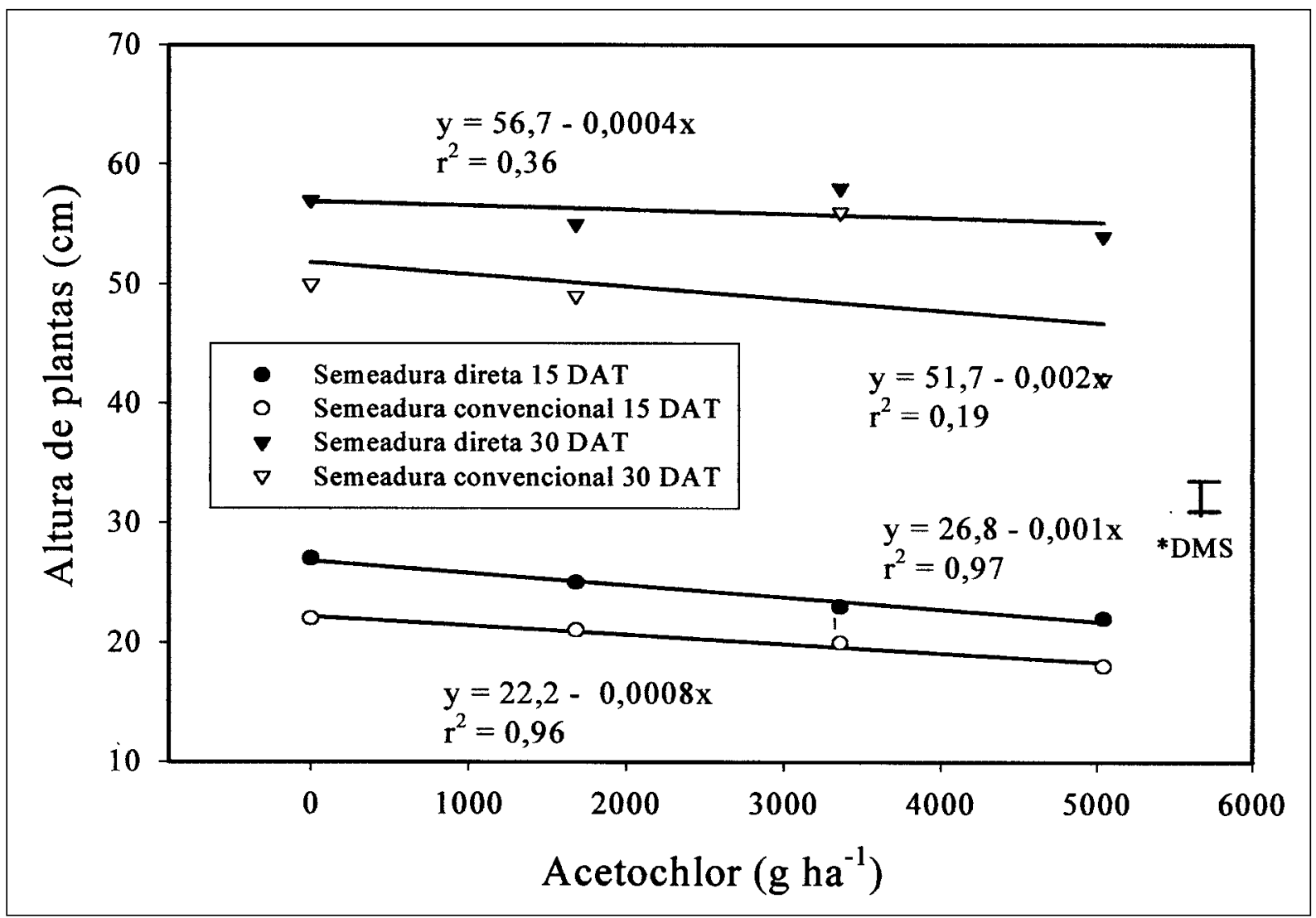

Figura 3 - Altura de plantas de milho em função do preparo do solo, doses e épocas de avaliação após aplicação do herbicida acetochlor. *DMS - Diferença mínima significativa ( $\mathrm{P} \leq 0,05)$. EEA/UFRGS, Eldorado do Sul, RS, 2000/2001.

Ciência Rural, v. 34, n. 2, mar-abr, 2004. 
Tabela 2 - Rendimento de grãos de milho em relação ao preparo e cobertura do solo com palha. EEA/UFRGS, Eldorado do Sul, RS, 2000/2001.

\begin{tabular}{ll}
\hline & $\begin{array}{c}\text { Rendimento de grãos de milho } \\
\left(\mathrm{kg} \mathrm{ha}^{-1}\right)\end{array}$ \\
& \multicolumn{1}{c}{ Preparo do solo } \\
\hline Semeadura direta & $7661,0 \mathrm{~b}^{1}$ \\
Preparo convencional & $8073,0 \mathrm{a}$ \\
CV $(\%)^{2}$ & 3,2 \\
& Cobertura do solo \\
Com palha & $7597,0 \mathrm{a}$ \\
Sem palha & $7183,0 \mathrm{~b}$ \\
CV $(\%)$ & 4,2 \\
\hline
\end{tabular}

${ }^{1}$ Médias seguidas pela mesma letra na coluna não diferem significativamente pelo teste Tukey $(\mathrm{P}>0,05)$.

${ }^{2} \mathrm{CV}=$ Coeficiente de variação.

vidade residual para controle das plantas daninhas pelo acetochlor entre os solos submetidos à semeadura direta e preparo convencional. A atividade e a persistência deste herbicida pode variar com o manejo, em função de alterações na adsorção, degradação e/ou transformação biológica e lixiviação (PETER \& WEBER, 1985; WALKER et al., 1992; MUELLER et al., 1999). Além disso, a presença da palha na superfície do solo, também pode afetar a atividade do herbicida acetochlor (BANKS \& ROBINSON, 1986). Desta forma, as variações nas características físicas, químicas e biológicas do solo decorrentes do manejo, aliado a presença da palha, podem ter conduzido a variação de controle das plantas daninhas observado neste trabalho.

\section{CONCLUSÕES}

Os resultados observados permitem concluir que o acetochlor foi mais eficiente no controle das plantas daninhas no Argissolo Vermelho sob preparo convencional, comparado à semeadura direta. A cobertura do solo com palha reduziu a eficácia de controle de plantas daninhas deste herbicida. O rendimento de grãos e a altura de plantas de milho foram superiores no preparo convencional e semeadura direta, respectivamente.

\section{REFERÊNCIAS BIBLIOGRÁFICAS}

ADDISCOTT, T.M.; DEXTER, A.R. Tillage and crop residue management effects on losses of chemicals from soils. Soil \& Tillage Research, Amsterdam, v.30, n.1, p.125-168, 1994.

BANKS, A.P, ROBINSON, E.L. Soil reception and activity of acetochlor, alachlor, and metolachlor as affeted by wheat (Triticum aestivum L.) straw and irrigation. Weed Science, Champaign, v.34, n.3, p.607-611, 1986.

DURIGAN, J.C. et al. Períodos de matocompetição na cultura da soja (Glycine max (L.) Merrill), cultivares Santa Rosa e IAC-2. I. Efeitos sobre os parâmetros de produção. Planta Daninha, Piracicaba, v.2, n.1, p.86-100, 1983.

FLECK, N.G.; MENGARDA, I.P.; PINTO, J.J.O. Interferência de plantas daninhas na cultura de girassol. Competição no tempo. Pesquisa Agropecuária Brasileira, Brasília, v.24, n.9, p.1139-1147, 1989.

FUSCALDO, F.; BEDMAR, F.; MONTERUBBIANESI, G. Persistence of atrazine, metribuzin and simazine herbicides in two soils. Pesquisa Agropecuária Brasileira, Brasília, v.34, n.11, p.2037-2044, 1999.

LEVANON, D. et al. Mobility of agrocemicals through soil from two tillage systems. Journal Environmental Quality, Madison, v.22, n.1, p.155-161, 1993.

MOYER, J.R. Effect of soil moisture on the efficacy and selectivity of soil-applied herbicides. Review of Weed Science, v.3, p.19-34, 1987.

MUELLER, T.C.; SHAW, D.R.; WITT, W.W. Relative dissipation of acetochlor, alachlor, metolachlor, and SAN 582 from three surface soils. Weed Science, Lawrence, v.13, n.1, p.341-346, 1999.

PETER, C.J.; WEBER, B.J. Adsorption, mobility and efficacy of alachlor and acetochlor as influenced by soil properties. Weed Science, Champaign, v.33, n.3, p.874-881, 1985.

PITELLI, R. A. Interferência de plantas daninhas em culturas agrícolas. Informe Agropecuário, Belo Horizonte, v.11, n. 129 , p. 16-27, 1985.

REDDY, K.N.; ZABLOTOWICZ, R.M.; LOCKE, M.A. Chlorimuron adsorption, desorption, and degradation in soils from conventional tillage and no-tillage systems. Journal Environmental Quality, Madison, v.24, n.2, p.760-767, 1995.

WALKER, A.; MOON, Y.; WELCH., S.J. Influence of temperature, soil moisture and soil characteristics on the persistence of alachlor. Pesticide Science, London, v.35, n.1, p.109-116, 1992.

WEBER, J.B.; PETER, C.J. Adsorption, bioactivity and evaluation of soil tests for alachlor, acetochlor and metolachlor. Weed Science, v.30, n.1, p.14-20, 1982. 